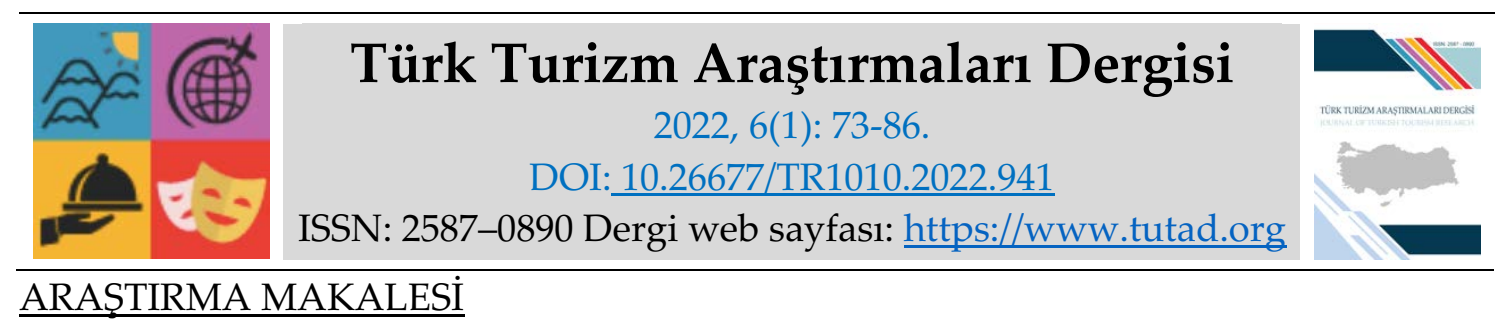

\title{
Çevresel Bilgi, Çevresel Farkındalık ve Çevresel Kaygının Çevre Dostu Otelde Kalma Niyeti Üzerindeki Etkisi: Su ve Atık Yönetimi Teknolojilerinin Rolü
}

Doç. Dr. Seden DOĞAN, Ondokuz Mayıs Üniversitesi, Turizm Fakültesi, Samsun, e-posta: seden.dogan@omu.edu.tr ORCID: https://orcid.org/0000-0001-8547-7702

Dr. Öğr. Üyesi Mehtap YÜCEL GÜNGÖR, Anadolu Üniversitesi, Turizm Fakültesi, Eskişehir, eposta: mehtapyg@anadolu.edu.tr ORCID: https://orcid.org/0000-0001-5212-8610

Doç. Dr. Ece ÖMÜRiş, Akdeniz Üniversitesi, Turizm Fakültesi, Antalya, e-posta: eceomuris@akdeniz.edu.tr

ORCID: https://orcid.org/0000-0002-1485-2816

Öz

Bu çalışmada geçen 12 ay içinde bir otelde konaklama gerçekleştirmiş misafirlerin çevresel bilgisi, çevresel farkındalığı ve çevresel kaygısının otellerde kullanılan su ve atık yönetimi teknolojilerine verdikleri önem üzerindeki etkisi ile bu teknolojilerin çevre dostu otelde konaklama niyeti üzerindeki etkisi araştırılmıştır. Çevrim içi veri toplama sistemi olan Amazon Mechanical Turk üzerinden veri toplanmıştır. Veri temizliği yapıldıktan sonra 498 kullanılabilir veri analize tabi tutulmuştur. Önerilen modelin ve hipotezlerin test edilmesi için Smart PLS paket programı kullanılmıştır. Yapılan analiz sonucunda değişkenlerin tümünün su ve atık yönetimi teknolojilerine verilen önemi, bu önemin de çevre dostu otelde kalma niyetini pozitif yönde anlamlı biçimde etkilediği tespit edilmiştir.

Anahtar Kelimeler: Çevresel Bilgi, Çevresel Farkındalık, Çevresel Kaygı, Çevre Dostu Otel, Su Yönetimi, Atık Yönetimi, Çevresel Teknolojiler, Yeşil Teknolojiler.

Makale Gönderme Tarihi: 07.01.2022

Makale Kabul Tarihi: 04.03.2022

\section{Önerilen Atıf:}

Doğan, S., Yücel Güngör, M. ve Ömüriş, E. (2022). Çevresel Bilgi, Çevresel Farkındalık ve Çevresel Kaygının Çevre Dostu Otelde Kalma Niyeti Üzerindeki Etkisi: Su ve Atık Yönetimi Teknolojilerinin Rolü, Türk Turizm Araştırmaları Dergisi, 6(1): 73-86.

(C) 2022 Türk Turizm Araştırmaları Dergisi. 


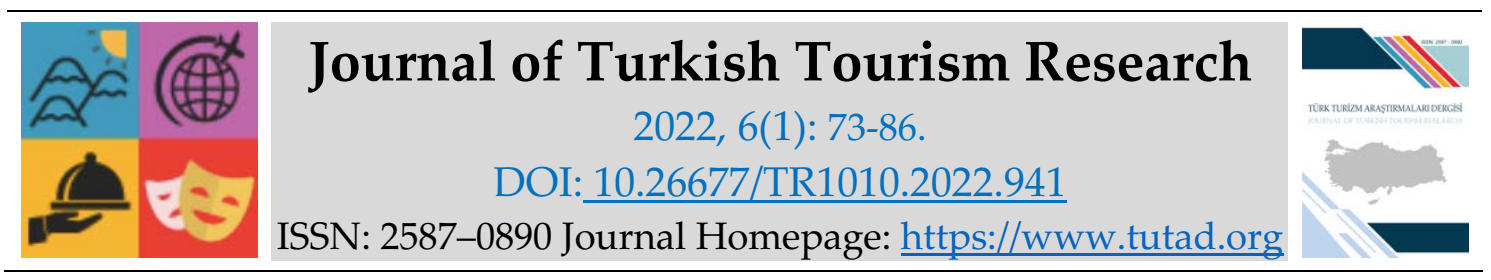

RESEARCH PAPER

\title{
Impact of Environmental Knowledge, Environmental Awareness and Environmental Concern on The Intention to Stay at An Environmentally Friendly Hotel: The Role of Water and Waste Management Technologies
}

Associate Prof. Dr. Seden DOĞAN, Ondokuz Mayıs University, Faculty of Tourism, Samsun, email: seden.dogan@omu.edu.tr

ORCID: https://orcid.org/0000-0001-8547-7702

Assistant Prof. Dr. Mehtap YÜCEL GÜNGÖR, Anadolu University, Faculty of Tourism, Eskişehir, e-mail: mehtapyg@anadolu.edu.tr

ORCID: https://orcid.org/0000-0001-5212-8610

Associate Prof. Dr. Ece ÖMÜRIŞ, Akdeniz University, Faculty of Tourism, Antalya, e-mail: eceomuris@akdeniz.edu.tr

ORCID: https://orcid.org/0000-0002-1485-2816

\begin{abstract}
In this study, the effect of environmental knowledge, environmental awareness and environmental concern of guests who have stayed in a hotel in the past 12 months on the importance given to water and waste management technologies used in hotels and the effect of these technologies on the intention to stay in an environmentally friendly hotel were investigated. Data were collected through Amazon Mechanical Turk, an online data collection system. After data cleaning, 498 usable data were analyzed. Smart PLS package program was used to test the proposed model and hypotheses. As a result of the analysis, it has been determined that all of the variables are important to water and waste management technologies, and this importance positively and significantly affects the intention to stay in an environmentally friendly hotel.
\end{abstract}

Keywords: Environmental Knowledge, Environmental Awareness, Environmental Concern, Environmentally Friendly Hotel, Water Management, Waste Management, Environmental Technologies, Green Technologies.

Received: 07.01.2022

Accepted: 04.03.2022

Suggested Citation:

Doğan, S., Yücel Güngör, M. and Ömüriş, E. (2022). Impact of Environmental Knowledge, Environmental Awareness and Environmental Concern on The Intention to Stay at An Environmentally Friendly Hotel: The Role of Water and Waste Management Technologies, Journal of Turkish Tourism Research, 6(1): 73-86.

(C) 2022 Türk Turizm Araştırmaları Dergisi. 


\section{Gíriş}

Çevre "canlıların içinde yaşadığı, hayati bă̆larla bağlı olduğu ve çeşitli şekillerde birbirlerini etkiledikleri ortam" olarak tanımlanmaktadır (Güneren Özdemir ve Tabak, 2019: 1754). Son yıllarda karşı karşıya kalınan küresel ısınma, iklim değişikliği, kaynakların azalması ve kirlilik gibi insanlığı bütünsel olarak etkileyen problemler çevreye yönelik duyarlılığı da artırmıştır (Oğuz ve Yılmaz, 2019). Çevresel bilgi, çevresel farkındalık ve çevresel kaygı ise bireylerin çevreye yönelik tutumlarını belirleyen unsurlardan bazılarıdır. Çevresel bilgi çevre ile ilgili sahip olunan bilgidir (Oflaç ve Göçer, 2015). Çevresel farkındalık çevre ile ilgili konulara yönelik sahip olunan farkındalıktır (Yalçınkaya, 2012). Çevresel kaygı ise çevreye yönelik duyulan endişedir (Kement, 2018). Çevresel sorunların arttığı ve bu sorunların neden olduğu olumsuzlukların önüne geçmenin en önemli yolunun, bireylerin çevre konusundaki tutumlarının ve bu tutumların birey davranışına etkisinin belirlenmesi olduğu ifade edilmektedir (Uzun ve Sağlam, 2007). Öte yandan turizm sektörü doğal çevreyle içi içe olan ve ekolojik çevreye bağımlıllğı olan bir sektördür. Bu sektörde faaliyet gösteren oteller de çevresel kaynakları yüksek düzeyde tüketen işletmelerdir. Çevreye yönelik duyarlılığın bir sonucu olarak ortaya çıkan çevre dostu oteller "dünyayı korumak için maddi tasarruf sağlarken aynı zamanda su tasarrufu, enerji tasarrufu ve katı atıkların azaltılmasına yönelik programlara katılmaya istekli yöneticileriyle, çevreyle dost işletmelerdir" (Korkmaz ve Atay, 2017: 115). Bu otellerde kullanılan enerji minimize edilmeye çalışılmakta, doğaya atılan katı ve sıvı atıkların hem miktarı azaltılmaya hem de ayrıştırılarak geri dönüşüme kazandırılmaya çalışılmaktadır (Chan, Okumus ve Chan, 2018).

Otellerde kullanılan çevresel teknolojilere yönelik akademik çalışmalar nispeten azdır (Chan vd., 2018). Bu çalışmada çevresel bilgi, çevresel farkındalık ve çevresel kaygının otellerde kullanılan su ve atık yönetimi uygulamalarına verilen öneme ve bu önem seviyesinin çevre dostu otellerde kalma niyetine etkisi araştııılmıştır.

\section{LITTERATÜR TARAMASI}

\section{Çevresel Bilgi}

Genel bir kavram olarak bilgi, bir bireyin bir konsepti yönelik anlayışın ve algısını ifade etmektedir. Çevresel bilgi (ÇB) ise çevre ile ilgili hususlarda belirlediği ve teyit ettiği bilgiyi kapsamaktadır. "Edinilen çevresel enformasyona göre çevre koruma ile ilgili sembolleri, kavramları ve davranış kalıplarını belirleme becerisi" olarak (Liobikiene ve Poskus, 2019) ya da "doğal çevre ve onun ana ekosistemleriyle ilgili gerçekler, kavramları ve ilişkiler hakkındaki genel bilgi" (Liu, Teng ve Han, 2020; Suki, 2013a) olarak tanımlanmaktadır. ÇB, çevresel davranışları gerçekleştirmek için entelektüel bir ön koşul olarak görülmektedir (Otto ve Pensini, 2017). Tüketicilerin tüketim davranışlarının çevre üzerindeki etkisine ve çevre dostu ürünlerin talebine olan değerlendirmeleri ve tepkileri ile ilgilidir. Öte yandan çevre ile insanlar arasındaki ilişkin hakkında sahip olunan bilgi olarak da tanımlanabilir. Bu tür bilgiler, bireyin çevreye karşı olan sorumluluğunu nasıl algıladığını ortaya çıarmakta ve onları çevreye yönelik çeşitli davranışlar sergilemelerine yol açmaktadır (Lin ve Niu, 2018; Paço ve Lavrador, 2017; Sun, Teh ve Linton, 2017). Sahip olunan çevresel bilginin yüksek düzeyde çevresel farkındalık yarattığı bilinmektedir (Kim, Kim ve Thapa, 2018; Suki, 2013a; He vd., 2011) Öte yandan ÇB, çevresel davranışları da etkilemektedir (Liu vd., 2020; Otto ve Pensini, 2017). Zira bu tür bilgiler bireyin çevreye karş1 kendi sorumluluğunu nasıl algıladığını ortaya koymaktadır (Lin ve Niu, 2018). Law, Hills ve Hau 
(2017), Zareie ve Navimipour (2016) ile Çetin Gürkan, Dönez Polat ve Demiralay (2015) yaptıkları araştırmalarda çevre bilgisinin, bireyin olumlu bir çevresel davranış sergilemesini sağladığını tespit etmişlerdir. Bu bilgiler ışığında aşağıdaki hipotezler geliştirilmiştir:

Hıa: Çevresel bilgi, çevresel farkındalığı pozitif yönde anlamlı şekilde etkilemektedir.

$\mathrm{H}_{1 b}$ : Çevresel bilgi, çevresel kaygıyı pozitif yönde anlamlı şekilde etkilemektedir.

$H_{1 c:}$ Çevresel bilgi, çevresel teknolojilerden su yönetimine verilen önemi pozitif yönde anlamlı şekilde etkilemektedir.

Hıd: Çevresel bilgi, çevresel teknolojilerden atık yönetimine verilen önemi pozitif yönde anlamlı şekilde etkilemektedir.

\section{Çevresel Farkındalık}

Farkındalık farkında olmak, tetikte olmak gibi anlamlara gelmektedir. Çevresel farkındalık ise çevresel konularda çeşitli kaynaklardan edinilen bilgiye dayalı farkındalıktır (Altın vd., 2014). Çevre dostu davranışlara yönelik öğrenme sürecinin ilk aşaması olarak kabul edilen çevresel farkındalık, iç ve dış pek çok faktörden etkilenmektedir. Ancak farkındalık tek başına yeterli değildir. Çevresel farkındalığa sahip olmanın yanı sıra, çevre ve çevre sorunları hakkında temel bir anlayışa, endişe duygularına, sorun çözme motivasyonuna sahip olmak ve bunları davranışa dökmek gereklidir (Kamaruddin, Ahmad ve Alwee, 2016). Bu bilgiler ışığında aşağıdaki hipotezler geliştirilmiştir:

H2a: Çevresel farkındalık, çevresel kaygıyı pozitif yönde anlamlı şekilde etkilemektedir.

$\mathrm{H}_{2 b}$ : Çevresel farkındalık, çevresel teknolojilerden su yönetimine verilen önemi pozitif yönde anlamlı şekilde etkilemektedir.

$\mathrm{H}_{2 c}$ : Çevresel farkındalık, çevresel teknolojilerden atık yönetimine verilen önemi pozitif yönde anlamlı şekilde etkilemektedir.

\section{Çevresel Kaygı}

Takacs-Santa (2007) çevresel kaygıyı çevresel bir tutum olarak ele almıştır. Ona göre çevresel kaygı, tutumun yapıcı boyutu olarak çevre dostu davranışa yatkınlığı ifade etmektedir. Çevresel kaygı, çevreye yönelik problemlere ilişkin kaygıyı ifade etmektedir (Eom vd., 2016). Yüksek düzeyde çevresel kaygısı olan bireylerin çevre dostu davranışları da yüksek düzeyde olmaktadır (Albayrak, Aksoy ve Caber, 2013). Araştırmacılar çevresel kaygının çevre dostu davranışların bir belileyicisi olduğunu ifade etmişlerdir (Kim ve Damhorst, 1998). Bang vd., (2000) çevresel kaygısı yüksek bireylerin, yenilebilir enerjiye daha çok ödeme yapmaya istekli olduklarını belirlemiştir. Atay, Soylu ve Gökdemir (2019) ile Nilsson ve Küller (2000) çevresel kaygının bireyleri çevre dostu uygulamaları kullanmaya yönelttiğini tespit etmişlerdir. Bu bilgiler ışığında aşağıdaki hipotez geliştirilmiştir:

$\mathrm{H}_{3}$ : Çevresel kaygı, çevresel teknolojilerden su yönetimine verilen önemi pozitif yönde anlamlı şekilde etkilemektedir. 
$H_{3 b}$ : Çevresel kaygı, çevresel teknolojilerden atık yönetimine verilen önemi pozitif yönde anlamlı şekilde etkilemektedir.

\section{Otellerde Kullanılan Çevresel Teknolojiler}

Oteller, evlere kıyasla belirgin miktarda doğal kaynak tüketen işletmelerdir. 7 gün 24 saat faaliyette olan oteller yüksek düzeyde elektrik, su, plastik ve gıda tüketimi yapmaktadırlar. Buna bağlı olarak da diğer binalara kıyasla daha fazla çevresel ayak izine sahiptirler (Chan, Okumus ve Chan, 2020; Chan, Okumus ve Chan, 2017). Bu soruna çözüm olması için pek çok işletme çevre dostu sistemleri entegre etmeye başlamışlardır. Bu sistemler oda doluluğunu gösteren sensörler, merkezi ısıtma ve soğutma sistemleri, LED özellikli ampüller, enerji tasarruflu ısıtma pompaları, su tasarrufu sağlayan sifonlar, kağıt israfını ortadan kaldırmak için dijital uygulamalar ve yemek atıklarını ayrıştııı mekanizmaları içermektedir (Chan vd., 2018). "Mamül veya hizmetlerin doğal çevre üzerindeki olumsuz etkilerini azaltan veya sinirlayan teknolojiler" (Shricastava, 2011: 185) olarak tanımlanan çevresel teknolojiler temelde iki grupta incelenmektedir (Chan vd., 2017; Zhan, Shen ve $\mathrm{Wu}, 2011)$. Birincisi isıtma ve soğutma için mekanik ekipman gerektirmeyen, bina mimarisinde düşük karbon emisyonlu malzemelerin kullanımıyla güneş enerjisinden optimum düzeyde yararlanan tasarımlardır. İkincisi ise bir alanı ısıtmak veya soğutmak için yapay, mekanik veya elektrik olarak çevresel teknolojilerin kullanılmasını gerektiren mekanik veya aktif tasarımlardır. Örneğin dış duvarlar, kapılar, pencereler, çatılar dahil olmak üzere bina gövdesinde kullanılan çevresel teknolojilerin çoğu aktif tasarımlardır (Zhang, Shen ve Wu, 2011). Klassen ve Whybark (1999) çevresel teknolojileri kirlenme önleyici, kirlenme kontrol ve yönetim sistemleri olarak üç gruba ayırmaktadır. Kirlenme önleyici teknolojiler, kirlilik kaynağında daha temiz çözümler kullanarak bu sorunu çözmektedir. Kirlenme kontrolü teknolojileri ise kirleticilerini salınımını azaltmakta, çevresel hasarı gidermekte ve atıkların uygun şekilde bertaraf edilmesini sağlamaktadır. Yönetim sistemleri, çevresel performansı iyileştirmeye yardımcı olan altyapı yatırımlarıdır. Enerji, su ve atık azaltma ve çevre bilinci, yeşil zamanlama ve çevre yönetim sistemi eğitimi örnek olarak verilebilir (Chan vd., 2017). Cheung ve Fan'a (2013) göre otellerde çevresel teknolojiler en çok aydınlatma, iklimlendirme, su isıtma ve soğutma, elektrik ve isı üretimi ile su temini alanlarında kullanılmaktadır. Otellerde en çok kullanılan kaynaklardan biri sudur. Su ve enerjinin birbiriyle bağlantılı olduğu düşünüldügüñnde makine ve donanımların çevre dostu olması, su tasarrufu sağlayacaktır. Otellerde olması beklenen bir diğer çevre dostu uygulama ise atık yönetimidir. Otellerde gün içerisinde çok fazla miktarda katı ve sıvı atık oluşmaktadır. Plastik, metal, cam, kağıt ve yiyecek-içecek atıklarının ayrıştırılması ve sınıflandırılarak geri dönüşümünün sağlanması önemlidir (Güneş, 2011).

\section{Çevre Dostu Otelde Kalma Niyeti}

Yapılan araştırmalar, çevre dostu ürünlere olan olumlu yaklaşımın ve çevreye yönelik kaygının çevre dostu ürün almayı tetiklediğini ortaya koymuştur (Kement, 2020; Hasnain vd., 2020). Ling Tan, Oluwaseyi Ojo ve Thurasamy (2019), Kar Yan ve Yazdanifard (2014), Suki (2013b) ve Bang vd. (2000) çevreye yönelik kaygıları ve hassasiyetleri olan tüketicilerin çevre dostu ürünlere satın almaya daha meyilli oldukların belirlemişlerdir. Çevre dostu otelleri ise "su ve enerji tasarrufu sağlayan, katı atıkları azaltan, geri dönüşüm ve yeniden kullanım programları uygulayan, sürdürülebilir çeore düzenlemeleri ve ekonomik çözümler geliştiren otellerdir" (Başgöze ve Bayar, 2015: 119). Oğuz ve 
Büyüker İşler (2020) ile Yıldız ve Kılıç (2016) turistlerin çevre dostu uygulamaları olan otellerde kalma niyetlerinin daha yüksek olduğunu tespit etmişlerdir. Bu bilgiler ışığında aşağıdaki hipotez geliştirilmiştir:

$\mathrm{H}_{4 a}$ : Çevresel teknolojilerden su yönetimine verilen önem çevre dostu otelde kalma niyetini pozitif yönde anlamlı şekilde etkilemektedir.

$\mathrm{H}_{4 b}$ : Çevresel teknolojilerden atık yönetimine verilen önem çevre dostu otelde kalma niyetini pozitif yönde anlamlı şekilde etkilemektedir.

\section{YÖNTEM}

\section{Araştırmanın Amacı ve Önemi}

Bu çalışmada geçen 12 ay içinde bir otelde konaklama gerçekleştirmiş misafirlerin çevresel bilgisi, çevresel farkındalığı ve çevresel kaygısının otellerde kullanılan su ve atık yönetimi teknolojilerine verdikleri önem üzerindeki etkisi ile bu teknolojilerin çevre dostu otelde konaklama niyeti üzerindeki etkisi araştırılmıştır. Daha önce yapılan araştırmalarda Çevresel bilgi, Çevresel farkındalık ve çevresel kaygının direkt olarak çevre dostu otelde konaklama niyeti üzerindeki etkisi araştırılırken bu çalışmada bu değişkenlerin su ve atık yönetimi teknolojilerine verilen öneme etkisi ve bu önem düzeyinin de çevre dostu otelde konaklama niyeti üzerindeki etkisi belirlenmeye çalışılmıştır.

\section{Veri Toplama Aracı}

Araştırmada veri toplama aracı olarak İnternet tabanlı anket kullanılmıştır. Ankette yer alan tüm değişkenler, literatürdeki farklı çalışmalardan derlenmiş ve 5'li Likert tipi ölçümleme ile ölçümlenmiştir. Çevresel Bilgi (EKNOW) ölçeği beş ifadeden oluşmaktadır ve Okumuş vd.,'nin (2019) çalışmalarından alınmıştır. Çevresel Farkındalık (EAWA) ölçeği yedi ifadeden oluşmaktadır ve Okumuş vd.,'nin (2019) çalışmalarından alınmıştır. Çevresel Kaygı (ECON) yedi ifadeden oluşmaktadır ve Okumuş vd.,' nin (2019) çalışmalarından alınmıştır. Su ve atık yönetimi teknolojileri dokuz maddeden oluşmaktadır ve Chan vd.,'nin (2017) çalışmalarından alınmıştır. Kalış Niyeti (INTST) ölçeği dört ifadeden oluşmaktadır ve Goelton vd.,'nin (2019) çalışmalarından alınmıştır.

Hazırlanan anket beş bölümden oluşmaktadır. İlk bölümde araştırmanın amacı hakkında bilgilendirme yapılmıştır ve cevaplayıcıların son 12 ay içinde en az bir kez bir otel konaklaması yapma şartını yerine getirip getirmediklerini belirlemeye yönelik bir soru sorulmuştur. Bu soruya hayır yanıtını verenler için anket otomatik olarak sonlandırılmıştır. İkinci bölümde çevresel bilgi, çevresel farkındalık, çevresel kaygı, su yönetimi teknolojileri ve atık yönetimi teknolojileri değişkenlerine ait ifadeler yer almaktadır. Üçüncü bölümde konaklama işletmelerindeki su ve atık yönetimi teknolojilerin ne kadar önemli olduğunu belirlemeye yönelik olarak dokuz maddelik liste bulunmaktadır. Dördüncü bölümde konaklama işletmesinde kalış niyetini belirlemeye yönelik ifadeler yer almaktadır. Beşinci ve son bölümde ise cevaplayıcıların demografik özelliklerini belirlemeye yönelik sorular yer almaktadır. 


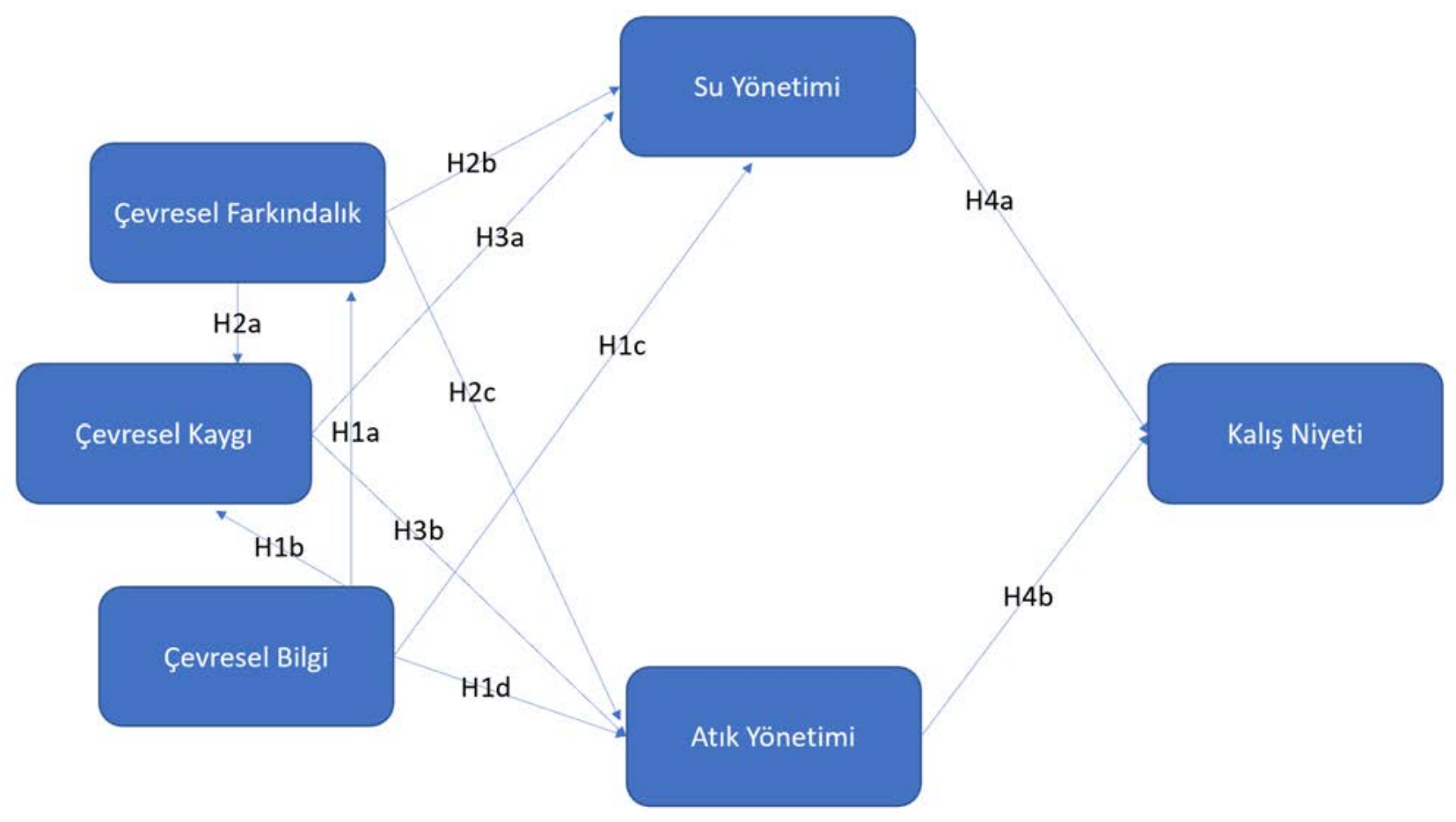

Şekil 1. Önerilen Model

\section{Analiz ve Bulgular}

Anket, Amazon Mechanical Turk (MTurk) çevrim içi anket sisteminden toplanmıştır. Literatürde MTurk'ün veri toplamak için güvenilir bir kaynak olduğunu belirten çalışmalar mevcuttur (Cheung vd., 2017; Rouse, 2015; Peer vd., 2014). Öte yandan anketin anonim olması ve gönüllülük esasıyla heterojen bir örneklem grubu tarafından doldurulmuş olması ortak metot yanlılığından kaçınmayı sağlamıştır (Shin, Hur ve Kang, 2016). Veri toplama süreci sonunda 563 kullanılabilir anket elde edilmiştir. Yapılan veri temizliği sonucunda 498 anket analize tabi tutulmuştur. Cevaplayıcılara ait bulgulara göre \%87'si Amerika Birleşik Devletlerinden ve \%11'i Güney Amerika ülkelerindendir. \%51'i erkek, \%49'u kadındır. \%46's1 40 yaş üzeri ve \%81'i evlidir. \%58'i lisans mezunudur.

Hipotezlerin ve modelin test edilmesi için Smart PLS 3.5 paket programı kullanılmıştır. Smart PLS kullanılmasının nedeni verinin normal dağılmaması ve ifadelerin formatif yapıda olmasıdır (Ali vd., 2018). Ölçüm modelinin yakınsak geçerliliğini değerlendirmek için faktör yükleri, bileşik güvenirlik (CR), Cronbach's Alpha, rho-A ve çıkarılan ortalama varyans (AVE) kullanılmıştır. Çevresel bilgi, çevresel farkındalık, çevresel kaygı ve su yönetimi değişkenlerinin faktör yükü 0.7'nin altındaki maddeleri analiz dışı bırakılmıştır. Maddeler çıkarıldıktan sonra yapılan analiz sonucu Tablo 1'de verilmiştir. Görüldüğü üzere AVE değerleri tavsiye edilen $0.5^{\prime}$ ten büyüktür (Hair vd., 2016). CA değerleri tavsiye edilen $0.5^{\prime}$ ten ve CR değerleri tavsiye edilen $0.7^{\prime}$ den büyüktür (Hair vd., 2013).

Ayırt edici geçerlilik, ampirik standartlara göre bir yapının diğer yapılardan ne kadar farklı olduğunu ifade etmektedir (Hair vd., 2016). Ayırt edici geçerliliği test etmek için Fornell ve Larcker'in (1981) kriteri kullanılmıştır. Tablo 2'de görüldüğü üzere tüm AVE diğerlerinin karekökü, karşılık gelen satır ve sütunlardaki diğer yapılarla olan korelasyondan daha büyüktür ve dolayısıyla yeterli ayırt edici geçerliliğgi göstermektedir (Ali ve Ali, 2022). 
Tablo 1. Değişkenlerin Faktör Yükleri ve Uyum Değerleri

\begin{tabular}{|lllllll|}
\hline Değişken & İfade & Faktör & CR & CA & rho-A & AVE \\
\hline \multicolumn{1}{l}{ Çevresel Bilgi } & Yükü & & & & \\
(ÇB) & EKNOW1 & 0.763 & 0.802 & 0.630 & 0.633 & 0.575 \\
& EKNOW2 & 0.712 & & & & \\
Çevresel Farkındalık & EKNOW4 & 0.799 & & & & \\
(ÇF) & EAWA2 & 0.782 & 0.796 & 0.615 & 0.614 & 0.566 \\
& EAWA6 & 0.755 & & & & \\
Çevresel Kayg1 & EAWA7 & 0.718 & & & & \\
(ÇK) & ECON1 & 0.736 & 0.817 & 0.664 & 0.665 & 0.598 \\
Su Yönetimi & ECON5 & 0.799 & & & & \\
(SY) & ECON7 & 0.784 & & & & \\
& WAT2 & 0.704 & 0.787 & 0.593 & 0.596 & 0.552 \\
Atık Yönetimi & WAT3 & 0.780 & & & & \\
(AY) & WAT5 & 0.743 & & & & \\
& WAST1 & 0.763 & 0.795 & 0.613 & 0.616 & 0.564 \\
Kalış Niyeti & WAST2 & 0.705 & & & & \\
(KN) & WAST3 & 0.783 & & & & \\
& INTST1 & 0.733 & 0.807 & 0.640 & 0.641 & 0.582 \\
& INTST2 & 0.745 & & & & \\
\hline
\end{tabular}

Tablo 2. Fornell ve Larcker Geçerliliği

\begin{tabular}{|lllllll|}
\hline & ÇF & ÇK & ÇB & KN & AY & SY \\
\hline ÇF & $\mathbf{0 . 7 5 2}$ & & & & & \\
\hline ÇK & 0.628 & $\mathbf{0 . 7 7 4}$ & & & & \\
\hline ÇM & 0.688 & 0.620 & $\mathbf{0 . 7 5 9}$ & & & \\
\hline KN & 0.731 & 0.640 & 0.719 & $\mathbf{0 . 7 6 3}$ & & \\
\hline AY & 0.621 & 0.638 & 0.607 & 0.682 & $\mathbf{0 . 7 5 1}$ & \\
\hline SY & 0.611 & 0.569 & 0.590 & 0.657 & 0.668 & $\mathbf{0 . 7 4 3}$ \\
\hline
\end{tabular}

\section{Yapisal Model}

Yapısal modelin ve hipotezlerin test edilmesi için Smart PLS 3.5 paket programı kullanılmıştır. Tablo 3'te görüldüğü üzere araştırma kapsamında kurulan hipotezlerin tamamı kabul edilmiştir. 


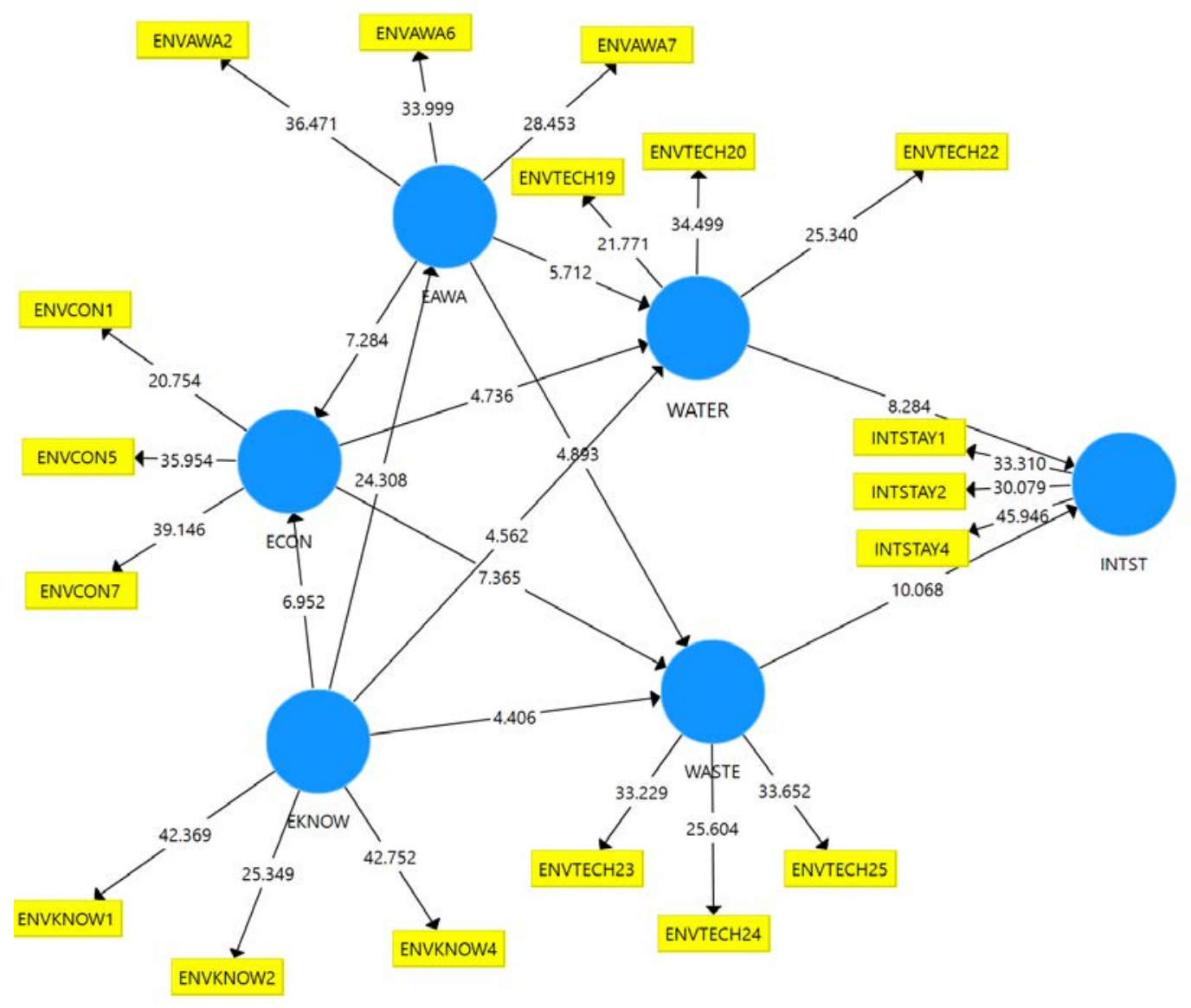

Şekil 2. Doğrulanan Model

Tablo 3. Hipotez Testi

\begin{tabular}{|llllll|}
\hline Hipotez No & Hipotez & Beta & $\mathbf{p}$ & T & Hipotez \\
\hline $\mathrm{H}_{1 a}$ & ÇB->ÇF & 0.688 & 0.000 & 24.308 & KABUL \\
\hline $\mathrm{H}_{1 \mathrm{~b}}$ & ÇB->ÇK & 0.356 & 0.000 & 6.952 & KABUL \\
\hline $\mathrm{H}_{1 \mathrm{c}}$ & ÇB->SY & 0.240 & 0.000 & 4.562 & KABUL \\
\hline $\mathrm{H}_{1 \mathrm{~d}}$ & ÇB->AY & 0.219 & 0.000 & 4.406 & KABUL \\
\hline $\mathrm{H}_{2 \mathrm{a}}$ & ÇF->ÇK & 0.383 & 0.000 & 7.284 & KABUL \\
\hline $\mathrm{H}_{2 \mathrm{~b}}$ & ÇF->SY & 0.301 & 0.000 & 5.712 & KABUL \\
\hline $\mathrm{H}_{2 \mathrm{c}}$ & ÇF->AY & 0.255 & 0.000 & 4.893 & KABUL \\
\hline $\mathrm{H}_{3 a}$ & ÇK->SY & 0.231 & 0.000 & 4.736 & KABUL \\
\hline $\mathrm{H}_{3 \mathrm{~b}}$ & ÇK->AY & 0.342 & 0.000 & 7.365 & KABUL \\
\hline $\mathrm{H}_{4 a}$ & SY->KN & 0.363 & 0.000 & 8.284 & KABUL \\
\hline $\mathrm{H}_{4 \mathrm{~b}}$ & $\mathrm{AYY}->\mathrm{KN}$ & 0.439 & 0.000 & 10.068 & KABUL \\
\hline
\end{tabular}

\section{SONUÇ ve TARTIŞMA}

Bu çalışmada geçen 12 ay içinde bir otelde konaklama gerçekleştirmiş misafirlerin çevresel bilgisi, çevresel farkındalı̆̆ı ve çevresel kaygısının otellerde kullanılan su ve atık yönetimi teknolojilerine verilen önem üzerindeki etkisi ile bu teknolojilerin çevre dostu otelde konaklama niyeti üzerindeki etkisi araştırılmıştır. Çevrim içi veri toplama sistemi olan Amazon Mechanical Turk üzerinden veri toplanmıştır. Veri temizliği yapıldıktan sonra 498 kullanılabilir veri analize 
tabi tutulmuştur. Önerilen modelin ve hipotezlerin test edilmesi için Smart PLS paket programı kullanılmıştır. Yapılan analiz sonucunda değişkenlerin tümünün su ve atık yönetimi teknolojilerine verilen önemi, bu önemin de çevre dostu otelde kalma niyetini pozitif yönde anlamlı şekilde etkilediği tespit edilmiştir. Su ve atık yönetime verilen önemi en fazla etkileyen iki değişken çevresel farkındalık ve çevresel kaygı iken, çevre dostu otelde kalma niyetini en fazla etkileyen değişken ise atık yönetimi teknolojilerine verilen önem olmuştur. Farklı çevresel teknolojilerin otel işletmelerinde pazarlama amaçlı kullanımının olumlu etkilerinden (Zografakis vd., 2011; Ruiz-Molina, Gil-Saura ve Moliner-Velazquezz, 2010) bahseden çalışmaların yanında çevresel tutumun çevre dostu otelde kalma niyetine etkisini araştıran çalışmalar (İşler ve Oğuz, 2020; Oğuz ve Yılmaz, 2019; Güneren Özdemir ve Tabak, 2019; Yıldız ve Kılıç, 2016; Çetin Gürkan vd., 2015) mevcuttur. Bu çalışma ise misafirlerin çevresel bilgisi, çevresel farkındalığı ve çevresel kaygısının otellerde kullanılan su ve atık yönetimi teknolojilerine verilen önem üzerindeki etkisi ile bu teknolojilerin çevre dostu otelde konaklama niyeti üzerindeki etkisini belirleyerek literatürdeki boşluğu doldurmaya katkı sunmuştur. Otel işletmelerinde en fazla tüketilen kaynaklardan biri olan su ile israf ve maliyet yaratan katı ya da sıvı atıkların yönetilmesinde teknolojik sistemlerden yararlanılması ve bunların pazarlama unsuru olarak kullanılması, mevcut ve potansiyel misafirlerin otel tercihini olumlu etkileyecektir.

\section{Sınırlılıklar, Varsayımlar ve Gelecekte Yapılabilecek Çalışmalar}

Bu çalışmanın pek çok diğer çalışma gibi bazı sınırlılıkları bulunmaktadır. Birinci sınırlılık örneklem ile alakalıdır. Analize tabi tutulan veri Amazon Mechanical Turk çevrim içi anket sisteminden toplanmış olduğu için sadece bu sisteme kayıtlı olan kullanıcılar örnekleme dahil edilebilmiştir. Bir diğer kısıtlılık katılımcıların bir yıl içinde en az bir kez bir otelde konaklama yapmış olma zorunluluğu olmasıdır. Öte yandan katılımcıların çevresel teknolojiler hakkında genel hatlarıyla da olsa bilgisi olduğu varsayılmıştır. Gelecekte örneklem genişletilebilir, farklı milliyetler ve yaş gruplarından katılımcılar araştırma kapsamında alınarak kültürlerarası ve kuşaklararası karşılaştırmalar yapılabilir. Benzer şekilde otel çalışanlarına yönelik araştırmalar yapılabilir. Model içerisine çevresel hassasiyet, çevresel anksiyete, enerji yönetimi teknolojileri gibi farklı değişkenleri eklenerek yeni çalışmalar yapılabilir.

\section{KAYNAKÇA}

Albayrak, T., Aksoy, Ş., and Caber, M. (2013). The effect of environmental concern and scepticism on green purchase behavior. Marketing Intelligence $\mathcal{E}$ Planning, 31(1), 27-39. https://doi.org/10.1108/02634501311292902

Ali, L., and Ali, F. (2022). Perceived risks related to unconventional restaurants: A perspective from edible insects and live seafood restaurants. Food Control, 131, 108471. https://doi.org/10.1016/j.foodcont.2021.108471

Ali, F., Rasoolimanesh, S. M., Sarstedt, M., Ringle, C. M., and Ryu, K. (2018). An assessment of the use of partial least square structural equation modeling (PLS-SEM) in hospitality research. International Journal of Contemporary Hospitality Research, 30(1), 514-538. http://dx.doi.org/10.1108/IJCHM-10-2016-0568 
Altın, A., Tecer, S., Tecer, L., Altın, S., and Kahraman B. F. (2014). Environmental awareness level of secondary school students: A case study in Balıkesir (Türkiye). Procedia-Social and Behavioral Sciences, 141, 1208-1214. https://doi.org/10.1016/j.sbspro.2014.05.207

Atay, L., Soylu, Y. ve Gökdemir, S. (2019). Çevre endişesi, Çevresel fedakarlık, normlar ve yer tutumunun çevre dostu davranışa etkisi: Kapadokya/Göreme Milli Parkı örneği. Seyahat ve Otel İsletmeciliği Dergisi, 16(3), 398-417.

Bang, H.-K., Ellinger, A. E., Hadjimarcou, J., and Traichal, P. A. (2000). Consumer concern, knowledge, belief, and attitude toward renewable energy: An application of the reasoned action theory. Psychology \& Marketing, 17(6), 449-468.

Başgöze, P. ve Bayar, N. A. (2015). Eko otellerden hizmet satın alımında kuşaklar arası farklılaşmalar üzerine bir çalışma. Sosyoekonomi, 23(24), 118-130. http://dx.doi.org/10.17233/se.40582

Chan, E. S. W., Okumuş, F., and Chan, W. (2020). What hinders hotels' adoption of environmental technologies: A quantitative study. International Journal of Hospitality Management, 84, 102324. https://doi.org/10.1016/j.ijhm.2019.102324

Chan, E. S. W., Okumuş, F., and Chan, W. (2018). Barriers to environmental technology adoption in hotels. Journal of Hospitality $\mathcal{E}$ Tourism Research, 42(2), 829-852. https://doi.org/10.1177/1096348015614959

Chan, E. S. W., Okumuş, F., and Chan, W. (2017). The applications of environmental technologies in hotels. Journal of Hospitality Marketing $\mathcal{E}$ Management, 26(1), 23-47. https://www.tandfonline.com/action/showCitFormats?doi=10.1080/19368623.2016.1176975

Cheung, J. H., Burns, D. K., Sinclair, R. R., and Sliter, M. (2017). Amazon Mechanical Turk in organizational psychology: An evaluation and practical recommendations. Journal of Business and Psychology, 32, 347-361.

Cheung, M., and Fan, J. (2013). Carbon reduction in high-density city: A case of Langham Place Hotel Mongkok Hong Kong. Renewable Energy, 5, 433-440. http://dx.doi.org/10.1016/j.renene.2012.06.060

Çetin Gürkan, G., Dönmez Polat, D. ve Demiralay, T. (2015). Turistlerde çevre bilincinin çevreye duyarlı müşteri davranışı ve çevreye duyarlı konaklama işletmelerinde kalma tercihleri üzerindeki etkisi. Ekonomi ve Yönetim Araştırmaları Dergisi, 4(1), 114-133.

Eom, K., Kim, H. S., Sherman, D. K., and Ishii, K. (2016). Cultural variability in the link between environmental concern and support for environmental action. Psychological Science, 27(10), 13311339. https://doi.org/10.1177/0956797616660078

Güneren Özdemir, E. ve Tabak, G. (2019). Turistlerin çevre dostu tutumlarının çevreye duyarlı turistik ürün satın alma niyeti üzerine etkisi: Nevşehir ilinde bir araştırma. Journal of Tourism and Gastronomy Studies, 7(3), 1753-1787. https://doi.org/10.21325/jotags.2019.447

Güneş, G. (2011). Konaklama sektöründe çevre dostu yönetimin önemi. KMÜ Sosyal ve Ekonomik Araştırmalar Dergisi, 13(20), 45-51.

Hair, J. F., Hault, G. T. M., Ringle, C., and Sarstedt, M. (2016). A primer on partial least squares structured equational modeling (PLS-SEM), London: Sage Publications.

Hair, J. F., Hult, G. T. M., Ringle, C., and Sarstedt M. (2013). A primer on partial least squares structural equation modelling (PLS-SEM), London: Sage Publications. 
Hasnain, A., Raza, S. H., and Qureshi, U. S. (2020). The impact of personal and cultural factors on green buying intentions with mediating roles of environmental attitude and eco-labels as well as gender as moderator. South Asian Journal of Management Science, 14(1), 1-27. https://doi.org/10.21621/sajms.2020141.01

He, X., Hong, T., Liu, L., and Tiefenbacher, J. (2011). A comparative study of environmental knowledge, attitudes, and behaviors among university students in China. International Research in Geographical and Environmental Education, 20(2), 91-104. https://doi.org/10.1080/10382046.2011.564783

İşler, D. ve Oğuz, R. (2020). Tüketicilerin çevre dostu tutumlarının yeşil otel tercihleri üzerindeki etkisi: Antalya ilinde bir uygulama. Mehmet Akif Üniversitesi Sosyal Bilimler Enstitüsü Dergisi, 32, 156-178. https://doi.org/10.20875/makusobed.625190

Kamaruddin, S. M., Ahmad, P., and Alwee, N. (2016). Community awareness on environmental management through Local Agenda 21 (LA21). Procedia - Social and Behavioral Sciences, 222, 729737. https://doi.org/10.1016/j.sbspro.2016.05.234

Kar Yan, Y., and Yazdanifard, R. (2014). The concept of green marketing and green product development on consumer buying approach. Global Journal of Commerce $\mathcal{E}$ Management Perspective, 3(2), 33-38.

Kement, Ü. (2020). Tüketici davranışlarının çevre dostu davranış türleri kapsamında incelenmesi: Alanya örneği. MANAS Sosyal Araştırmalar Dergisi, 9(1), 209-221.

Kement, Ü. (2018). Çevresel kaygı ve algılanan ahlaki yükümlülüğün yeşil otelleri ziyaret etme niyetine etkisinin belirlenmesi. Turizm Akademik Dergisi, 5(2), 203-214.

Kim, M.-S., Kim, J., and Thapa, B. (2018). Influence of environmental knowledge on affect, nature affiliation and pro-environmental behaviors among tourists. Sustainability, 10(9), 3109. https://doi.org/10.3390/su10093109

Kim, H.-S., and Damhorst, M. L. (1998). Environmental concern and apparel consumption. Clothing and Textiles Research Journal, 16(3), 126-133.

Klassen, R. D., and Whybark, D. C. (1999). The impact of environmental technologies on manufacturing performance. Academy of Management Journal, 42(6), 599-615. http://dx.doi.org/10.2307/256982

Korkmaz, H. ve Atay, L. (2017). Otel işletmelerinde yeşil pazarlama ve çevre sertifikalarının değerlendirilmesi. Aksaray Üniversitesi İ̈BF Dergisi, 9(4), 113-126.

Law, M. M. S., Hills, P., and Hau, B. C. H. (2017). Engaging employees in sustainable development: A case study of environmental education and awareness training in Hong Kong. Business Strategy and the Environment, 26(1), 84-97. http://dx.doi.org/10.1002/bse.1903

Lin, S.-T., and Niu, H.-J. (2018). Green consumption: Environmental knowledge, environmental consciousness, social norms, and purchasing behavior. Business Strategy and the Environment, 27(8), 1679-1688.

Law, M. M. S., Hills, P., and Hau, B. C. H. (2017). Engaging employees in sustainable development-A case study of environmental education and awareness training in Hong Kong. Business Strategy and the Environment, 26(1), 84-97.

Ling Tan, C. N., Oluwaseyi Ojo, A., and Thurasamy, R. (2019). Determinants of green product buying decision among young consumers in Malaysia. Young Consumers, 20(2), 121-137. http://dx.doi.org/10.1108/YC-12-2018-0898 
Liobikiene, G., and Poskus, M. S. (2019). The importance of environmental knowledge for private and public sphere pro-environmental behavior: Modifying the value-belief-norm theory. Sustainability, 11(12), 3324. https://doi.org/10.3390/su11123324

Liu, P., Teng, M., and Han, C. (2020). How does environmental knowledge translate into proenvironmental behaviors? The mediating role of environmental attitudes and behavioral $\begin{array}{llllll}\text { intentions. Science of the Total Environment, } & 728,126 .\end{array}$ https://doi.org/10.1016/j.scitotenv.2020.138126

Nilsson, M., and Küller, R. (2000). Travel behavior and environmental concern. Transportation Research Part D, 5, 211-234.

Oflaç, B. S. ve Göçer, A. (2015). Genç tüketicilerin algılanan çevresel bilgi düzeyleri ve eko-etiketli ürünlere karşı yaklaşımları üzerine bir araştırma. Gazi Üniversitesi İ̈BF Dergisi, 17(2), 216-228.

Oğuz, R. ve Büyüker İşler, D. (2020). Tüketicilerin çevre dostu tutumlarının yeşil otel tercihleri üzerindeki etkisi: Antalya ilinde bir uygulama. Mehmet Akif Ersoy Üniversitesi Sosyal Bilimler Enstitüsü Dergisi, 32, 156-178.

Oğuz, Y. E. ve Yılmaz, V. (2019). Çevre bilincinin yeşil yıldızlı otel tercihine etkisi: ESOGÜ Turizm Fakültesi öğrencileri örneği. Eskişehir Osmangazi Üniversitesi İIBF Dergisi, 14(1), 51-66.

Otto, S., and Pensini, P. (2017). Nature-based environmental education of children: Environmental knowledge and connectedness to nature, together, are related to ecological $\begin{array}{lllll}\text { behavior. Global Environmental } & \text { Change, } & \text { 47, }\end{array}$ http://dx.doi.org/10.1016/j.gloenvcha.2017.09.009

Paço, A., and Lavrador, T. (2017). Environmental knowledge and attitudes and behaviors towards energy consumption. Journal of Environmental Management, 197, 384-392. http://dx.doi.org/10.1016/j.jenvman.2017.03.100

Peers, E., Vosgreau, J., and Acquisti, A. (2014). Reputation as a sufficient condition for data quality on Amazon Mechanical Turk. Behavior Research Methods, 46, 1023-1031.

Rouse, S. V. (2015). A reliability analysis of Mechanical Turk data. Computers in Human Behavior, 43, 304-307.

Ruiz-Molina, M.- E., Gil-Saura, I., and Moliner-Velazquez, B. (2010). Good environmental practices for hospitality and tourism. Management of Environmental Quality: An International Journal, 21(4), 464-476. https://doi.org/10.1108/14777831011049106

Shin, I., Hur, W.-M., and Kang, S. (2016). Employees' perceptions of corporate social responsibility and job performance: A sequential mediation model. Sustainability, 8(5), 493. https://doi.org/10.3390/su8050493

Shrivastava, P. (1995). Environmental technologies and competitive advantage. Strategic Management Journal, 16(1), 183-200.

Suki, N. M. (2013a). Young consumer ecological behavior. Management of Environmental Quality: An International Journal, 24(6), 726-737. http://dx.doi.org/10.1108/MEQ-02-2013-0010

Suki, N. M. (2013b). Green awareness effects on consumers' purchasing decision: Some insights from Malaysia. IJAPS, 9(2), 49-63.

Sun, H., Teh, P.-L., and Linton, J. D. (2017). Impact of environmental knowledge and product quality on student attitude toward products with recycled/remanufactured content: Implications for environmental education and green manufacturing. Business Strategy and the Environment, 27, 935-945. https://doi.org/10.1002/bse.2043 
Takacs-Santa, A. (2007). Barriers to environmental concern. Human Ecology Review, 14(1), 26-38.

Uzun, N. ve Sağlam, N. (2007). Ortaöğretim öğrencilerinin çevreye yönelik bilgi ve tutumlarına çevre ve insan dersi ile ilgili gönüllü çevre kuruluşlarının etkisi. Hacettepe Üniversitesi Eğitim Fakültesi Dergisi, 33, 210-218.

Yalçınkaya, E. (2012). İlköğretim 6. sınıf öğrencilerinin çevre sorunları farkındalık düzeyleri. Marmara Coğrafya Dergisi, 25, 137-151.

Yıldız, S. B. ve Kılıç, S. N. (2016). Alman turistlerin çevre bilinci ve çevre dostu otel (yeşil otel) algısının davranışsal niyetleri üzerindeki etkisi. Uluslararası Sosyal Araştırmalar Dergisi, 9(43), 2614-2623.

Zareie, B. and Navimipour, N. J. (2016). The impact of electronic environmental knowledge on the environmental behaviors of people. Computers in Human Behavior, 59, 1-8. http://dx.doi.org/10.1016/j.chb.2016.01.025

Zhang, X. L., Shen, L. Y., and Wu, Y. Z. (2011). Green property development practice in China: Cost and barriers. Building and Environment, 46, 2153-2160.

Zografakis, N., Gillas, K., Pollaki, A., Profylienou, M., Bounialetou, F., and Tsagarakis, K. P. (2011). Assessment of practices and technologies of energy saving and renewable energy sources in hotels in Crete. Renewable Energy, 36, 1323-1328. http://dx.doi.org/10.1016/j.renene.2010.10.015 